\title{
Cost effectiveness of proprotein convertase subtilisin/ kexin type 9 (PCSK9) inhibitors
}

\author{
Abdulhalim Jamal Kinsara* \\ Department of cardiology, Ministry of National Guard health Affair, King Abdullah International medical research center, King Saud Bin Abdulaziz University for \\ health sciences-COM. Jeddah, Saudi Arabia
}

\begin{abstract}
The cost effectiveness of Proprotein Convertase Subtilisin/Kexin Type 9- (PCSK9) inhibitors was a global concern, we here elaborate on the analysis done in different countries and explore the unseen part of such analysis. A guideline-based approach with careful monitoring the use and delivered price will minimize the concern regarding cost effectiveness of PCSK9 inhibitors.
\end{abstract}

Proprotein Convertase Subtilisin/Kexin Type 9 (PCSK9)-inhibitors are a recently approved class of lipid lowering therapy that showed a significant decrease in absolute combined composite of CV death, MI, stroke, hospitalization for UA, or coronary revascularization by $1.5 \%$. This effect was the result of a 55\% LDL reduction, with associated $7 \%$ elevation of HDL.

However, one of the major challenges for its wide use was the cost. Herewith, we review the current cost data to see if it is cost effective or not in different countries and whether it is class effect or individual medication.

The topic is a hot issue, JAMA and JAMA Cardiology have published three separate cost-effectiveness analyses [1-3]. PCSK9 inhibitors were never found to be cost-effective in primary prevention. In secondary prevention, the initial estimate of the cost in the original forrier study for evolucumab ranged from 14,000-15,000 \$ dollars annually. This value was labeled expensive [4]. Five years treatment for 10 million potentially eligible US patients would cost $\$ 600$ billion, 38\% more than the entire cost of all prescription drugs in 2015.

In the USA, it had been reported that for PCSK9-inhibitors to be cost-effective, a reduction of the price to $\$ 5459$ ( 62\% of its current value) is required based on the initial data. These data were based on quality-adjusted life-years in the USA calculated as \$100 000 per quality-adjusted life-year [5].

The cost effectiveness was published based on Institute for Clinical and Economic Review Draft Report Published online 8 September 2015 [6-10]. A benchmark based upon the country's domestic product per capita. If the value exceeds three times GDP, then it is viewed as economically unattractive.

In Canada, applying the "what-if" principle, the authors suggest that nearly every 1 in 2 patients with established CVD in Ontario would be eligible for PCSK9- inhibitors. They conclude that PCSK9-inhibitors could deter $>1000$ primary cardiovascular events in the next 3 years, with a potential downstream cost saving of $\approx \$ 43.9$ million. The annual cost in Canada being one third of that in the USA but for all eligible candidates, cost will be $\approx \$ 1.5$ billion Canadian dollars [11].
In the UK, the annual cost of evolocumab per patient every two weeks is $£ 4,448.60$ and $£ 4,383$ for Alirocumab, compared with $£ 350.00$ for ezetemibe. NICE guidance recommends PCSK9 as cost effective in patients with LDL-C $>3.5 \mathrm{mmol} / \mathrm{l}$ in patient having CVD with heterozygous familial hypercholesterolaemia or at very high risk for CVD events without $\mathrm{HeFH}$ after applying unknown percent discounts that were agreed with the companies [12].

In Norway, the lowest cost-effectiveness ratios were for heterozygous familial hypercholesterolaemia patients and high-risk diabetics, with $€ 63,200$ and $€ 68,400$ per quality-adjusted life-year (QALYs), respectively. PCSK9 inhibitors are found, in the model, to be cost-effective only in secondary prevention for older patients with high absolute risk of CVD [13].

Similar data was noted in Japan, where the incremental cost effectiveness ratio (ICER), expressed as QALYs, found that based on a threshold of 5 million JPY, PCSK9 inhibitor plus statin did not show good cost-effectiveness for triple-vessel CAD; however, it showed good cost-effectiveness for patients with triple-vessel CAD and poorly controlled FH [14].

A similar calculation in Australia revealed similar conclusions. In order to reach a threshold of AU\$50,000 per QALYs, saved, the price reduction was estimated to be AU $\$ 1500$ per person per annum for PCSK9i to reach the arbitrary cost-effectiveness instead of the current AU\$8174 [15].

The story was not different with Alirocumab. It was cost effective at a price up to 6,319 \$ per year at the $100,000 \$$ willingness to

*Correspondence to: Abdulhalim Jamal Kinsara, department of cardiology, Ministry of National Guard health Affair, Jeddah, King Abdullah International medical research center, King Saud Bin Abdulaziz University for health sciences-COM, Mail code 6599, P.O. Box 9515, Jeddah 21423, Saudi Arabia; Tel: 966-12-2266666, ext: 25797; E-mail: kinsaraaj@ngha.med.sa

Key words: coronary artery disease, cost-effectiveness, PCSK9 inhibitors

Received: January 21, 2019; Accepted: February 04, 2019; Published: February 08,2019 
pay threshold. The cost was applied to cardiovascular death and recurrent non-fatal events including myocardial infarction, ischemic stroke, coronary revascularization and unstable angina requiring hospitalization in patients $<65$ years of age in those with LDL-C $\geq 100$ $\mathrm{mg} / \mathrm{dL}$ or less. At any level of willingness to pay, cost-effectiveness is greater in patients with baseline LDL-C values $\geq 100 \mathrm{mg} / \mathrm{dL}$ in comparison to those $<100 \mathrm{mg} / \mathrm{dL}$. Of note diabetics were not included in the above analysis [16].

Value-based price benchmark range of 100,000-150,000 \$ per QALYs, alirocumab's price should be 2,300-3,400 \$ per year if used to treat all patients who meet trial eligibility criteria, and 4,500-8,000 \$ per year if used as primary prevention to treat only higher-risk patients with LDL-C $\geq 100 \mathrm{mg} / \mathrm{dL}$ despite intensive statin therapy [17].

These analyses were based on QALYs based benchmarks but there are important issues that we need to consider before making such a conclusion \%. In actual practice, many of these patients with high LDL were not on statin at all or not on maximum dose. One study reported 1 in 5 of these patients were not receiving a statin and less than half were on a high-intensity dose. Applying the existing clinical guidelines, this may reduce the number of eligible patients by half [12].

On the basis of a recent subanalysis from the FOURIER trial focusing on PCSK9-inhibitors among the highest-risk groups, such as those with recent acute coronary syndrome, those with symptomatic peripheral arterial disease, or those who are post-myocardial infarction with at least 1 high-risk feature, may result in a bearable budgetary burden on health systems [14].

PCSK 9 are initiated in hospitals at specialist clinics therefore they are unlikely to be overprescribed. Prior authorization requirements will also cut the cost as a recent study indicates that $40 \%$ of patients prescribed PCSK9-inhibitors did not have cardiovascular disease (an entry criterion for the randomized controlled trials) and half were not taking a statin [10].

Value should be periodically reassessed, and prices should be adjusted.

Unfortunately, such analysis also omitted the observation that patients with rejected PCSK9 prescription had 7.29 CV event rate at 6 months compared to 6.73 event in the group whose prescription had been approved.

On the other hand, the cost was compared with annual costs of generic statin therapy that is estimated around $485 \$$ [4]. Many experts in the lipid field believe that economic value will be in favor of PCSK9 group if the promising clinical outcome were given its merit and the scale of these outcome benefits were evaluated in large randomized trials.

This will underline the importance of what organization should conduct CEAs? In addition to encouraging other manufacturers to take the same action, and drop drug prices to those established by CEAs? $[18,19]$.

It should be noted that the benefits and budget implication were counted over a 3 years period; a more prolonged frame might change the cost impact significantly.

In fairness to industrial companies, innovation should be encouraged, rather than just cost containment. \% A market and policies solution like the NICE approach seems to be a reasonable one.
\% Management guidelines need to broaden perspective balancing costs and benefits and the concept of what we get for what we pay?

PCSK 9 manufacturers announced price reductions of thousands of dollars annually, meeting the price suggested by the Institute for Clinical and Economic Review's revised CEAs.

\section{Conclusion}

A guideline-based approach with careful monitoring the use and delivered price will minimize the concern regarding cost effectiveness of PCSK9 inhibitors.

\section{Acknowledgement}

I would like to thank Mrs. Noura Pellicci for her help in typing the manuscript.

\section{References}

1. Bonow RO, Harrington RA, Yancy CW (2017) Cost-effectiveness of PCSK9 Inhibitors: Proof in the Modeling. JAMA Cardiol 2: 1298-1299. [Crossref]

2. Dennis T Ko, Anam M. Khan, Gynter Kotrri, Peter C Austin, Harindra C, et al. (2018) Eligibility, Clinical Outcomes, and Budget Impact of PCSK9 Inhibitor Adoption: The CANHEART PCSK9 Study. JAHA 7: e010007

3. Anderson JL, Heidenreich PA, Barnett PG, Creager MA, Fonarow GC, et al. (2014) ACC/AHA statement on cost/value methodology in clinical practice guidelines and performance measures: a report of the American College of Cardiology/American Heart Association Task Force on Performance Measures and Task Force on Practice Guidelines. Circulation 129: 2329-2345. [Crossref]

4. Ohad Oren and Michal Oren (2018) Cost effectiveness of an outcome-based reimbursement model of pcsk9 inhibitors. $J A C C$

5. Arrieta A, Hong JC, Khera R, Virani SS, Krumholz HM, et al. (2017) Updated costeffectiveness assessments of PCSK9 inhibitors from the perspectives of the health system and private payers: insights derived from the FOURIER Trial. JAMA Cardiol. [Crossref]

6. Kazi DS, Moran AE, Coxson PG, Penko J, Ollendorf DA, et al. (2016) Cost-effectiveness of PCSK 9 inhibitor therapy in patients with homozygous familial hypercholesterolemia or atherosclerotic cardiovascular disease. JAMA 316: 743-753. [Crossref]

7. Gandra SR, Villa G, Fonarow GC, Lothgren M, Lindgren P, et al. (2016) CostEffectiveness of LDL-C Lowering With Evolocumab in Patients With High Cardiovascular Risk in the United States. Clin Cardiol 39: 313-320. [Crossref]

8. Robinson JG, Huijgen R, Ray K, Persons J, Kastelein JJ, et al. (2016) Determining When to Add Nonstatin Therapy: A Quantitative Approach. J Am Coll Cardiol 68: 2412-2421. [Crossref]

9. Stam-Slob MC, van der Graaf Y, de Boer A, Greving JP, Visseren FLJ (2018) Costeffectiveness of PCSK9 inhibition in addition to standard lipid-lowering therapy in patients at high risk for vascular disease. Int J Cardiol 253: 148-154. [Crossref]

10. Arrieta A, Page TF, Veledar E, Nasir K (2017) Economic evaluation of PCSK9 inhibitors in reducing cardiovascular risk from health system and private payer perspectives. PLoS One 12: e0169761. [Crossref]

11. Dennis T Ko, Anam M Khan, Gynter Kotrri, Peter C Austin, Harindra C, et al. (2018) Eligibility, Clinical Outcomes, and Budget Impact of PCSK9 Inhibitor Adoption: The CANHEART PCSK9 Study. JACC.

12. Torjesen I (2016) NICE draft guidance recommends PCSK9 inhibitors for high risk cardiovascular patients. Pharm J 296: 20201125.

13. Max Korman, Torbjørn Wisløff (2018) Modelling the cost-effectiveness of PCSK9 inhibitors vs. ezetimibe through LDL-C reductions in a Norwegian setting. Eur Heart $\mathrm{J}$ Cardiovasc Pharmacother 4: 15-22. [Crossref]

14. Kodera S, Morita H, Kiyosue A, Ando J, Takura T, et al. (2018) Cost-Effectiveness of PCSK9 Inhibitor Plus Statin in Patients With Triple-Vessel Coronary Artery Disease in Japan. Circ J 82: 2602-2608. [Crossref]

15. Kumar R, Tonkin A, Liew D, Zomer E (2018) The cost-effectiveness of PCSK9 inhibitors - The Australian healthcare perspective. Int J Cardiol 267: 183-187. [Crossref] 
16. Sanket S Dhruva, Joseph S Ross, Nihar R Desai (2018) Alirocumab's Price Reduction, Implications of a Paradigm Shift Toward Cost-Effective Pricing. Circulation 138: $1502-1504$

17. Institute for Clinical and Economic Review (2018) Alirocumab for Treatment of High Cholesterol: Effectiveness and Value. Preliminary New Evidence Update.
18. Virani SS, Akeroyd JM, Nambi V, Heidenreich PA, Morris PB, et al. (2017) Estimation of eligibility for PCSK9 inhibitors and associated costs based on the FOURIER trial: insights from the Department of Veterans Affairs. Circulation 135: 2572-2574. [Crossref]

19. Nasir K (2018) Just Price for PCSK9 Inhibitors: No less, No More. J Am Heart Assoc 7: e010884. [Crossref]

Copyright: (C2019 Kinsara AJ. This is an open-access article distributed under the terms of the Creative Commons Attribution License, which permits unrestricted use, distribution, and reproduction in any medium, provided the original author and source are credited. 